\title{
Insecticides and World Health
}

\author{
WHO Expert Committee on Insecticides
}

By SAMUel W. SIMMONS, Ph.D.

The World Health Organization is a specialized agency of the United Nations and represents the culmination of efforts to establish a single intergovernmental health agency. It is the first intergnvernmental institution to adopt the term "world" as part of its title. Disease knows no frontiers, and anything less than world action not only may deprive one nation of the benefits of WHO but may endanger the health of all member states.

WHO had its origin in the proposal, made at the United Nations Conference held in San Francisco in 1045 , that a specialized agency be created to deal with all matters relating to health. In 1946, representatives of 61 governments met at the International Health Conference in New York, where they drafted and signed the WHO constitution and established an Interim Commission to serve until the constitution could be ratified by 26 member states of the United Nations. The constitution came into force on April 7, 1948; the First World Health Assembly met in Geneva in June 1948; and on September 1, 1948, the permanent organization was established.

The work of WHO is carried out by three organs: (1) the World Health Assembly, the supreme authority, to which all member states send delegates; (2) the Executive Board, the executive organ of the Health Assembly, con-

Dr. Simmons is the chief of the technical development branch of the Communicable Disease Center, Public Health Service, Atlanta, Ga., and is a member of the Expert Committee on Insecticides of the World Health Organization. sisting of 18 persons designated by as many member states; and (3) a Secretariat, under the Director-General.

During the first ferw months of the existence of WHO, plans were prepared and operations were begun for launching offensives against disease. Expert committees, made up of international experts, advised the Director-General on the planning of immediate and long-term programs for improving world health.

Milaria, which still attacks, incapacitates, and kills millions of people in many parts of the world, but which lends itself to effective new measures of prevention and treatment, was one of the first disenses to which IVHO gave special attention. The Interim Commission recognized that the problem of maluria was sufficiently urgent and important to warrant immediate action; an Expert Committee on Malaria was therefore established.

\section{Committee Established}

The Expert Committee on Malaria, at their second session in Washington, D. C., May 19-25, 1948, recommended that an Expert Committee on Insecticides be set up to specify international standards for insecticides and their formulations, to stimulate the development of standard spraying equipment on a regional basis, and to deal with all other questions relating to the proper use of insecticides. In response to these recommendations, an Expert Committee on Insecticides was established.

The original committee consisted of three members. In May 1950, however, the World Health Assembly authorized the appointment 
of an expert advisory panel, from which a small number of experts are drawn to attend each meeting, depending upon the subjects to be considered.

\section{First Session}

The Expert Committee on Insecticides held its first session in Cagliari, Sardinia, May 1015, 1949 (1). This choice of location afforded members the opportunity of gaining first-hand knowledge of the work being carried out in Sardinia under the joint auspices of the Italian Government and the Rockefeller Foundation (Ente Regionale per la Lotta Anti Anofelica in Sardegna-ERLAAS) in freeing the island of malarial mosquitoes by means of insecticides.

In addition, the committee was able to study the measures developed for preventing the reinfestation of the island from sea or air. Therefore, this group was in a position to make suggestions to the Expert Committee on International Epidemiology and Quarantine for the drafting of WHO regulations on the disinsectization of ships and aircraft.

The terms of reference of the committee were the following:

1. To advise the Expert Committee on $\mathrm{Ma}$ laria regarding specifications of international standards for insecticides and their formulations for use against vectors of the disease, and of standard spraying equipment for malaria control and its adaptability to regional conditions.

2. To draw up a standard method of disinsectization of ships and aircraft, to be submitted to the WHO Expert Committee on International Epidemiology and Quarantine for consideration in the drafting of WHO sanitary regulations.

3. To make recommendations concerning measures that might be given general application for the prevention of the introduction of anophelines into areas free or freed from them.

The work of the committee at this meeting included the drafting of specifications for DDT. Specifications used in the United States and the United Kingdom for commercial DDT were utilized as a basis for these specifications. In view of the number and diversity of insecticidal preparations and the paucity of knowledge concerning many of the new ones, it was impossible to fix specifications for other insecticides at that time.

The committee restricted itself to laying down the general requirements which should be satisfied by the various types of both compression and hand sprayers, since it was considered that it would be impracticable to market a single model suitable for use in all regions of the world and complying with all requirements. The draft specifications referred to the materials utilized, capacity, and weight, as well as to certain points relating to the construction of the different component parts of the sprayer. Several technical improvements were recommended.

With reference to the disinsectization of ships, the committee adopted in principle the regulations, drawn up by ERLAAS, which were intended to prevent the reintroduction of anophelines into the island of Sardinia. These regulations provided essentially for antianopheline treatments of all ships arriving in Sardinia from specified areas. The committee also had the opportunity of attending disinsectization operations carried out aboard a cargo vessel and of judging the efficacy of the methods recommended. The disinsectization of a cargo vessel of 2,000 tons takes $11 / 2$ hours.

The committee was of the opinion that disinsectization of ships and aircraft when carried out efficiently constituted a safeguard against the introduction of anophelines. It was thought that the same methods should be considered for road traffic whenever necessary. However, the application of disinsectization measures, by quarantine services at ports and frontiers, can never insure complete protection; it is essential that systematic campaigns against anophelines be instituted in areas where malaria is endemic and that surveillance be continued in those areas which have been freed from the pests, so that immediate steps may be taken in the event of the accidental introduction or reintroduction of the insects. In regions which have been freed from anophelines, the use of residual insecticides for controlling domestic insects is an effective means of destroying introduced mosquitoes.

The committee also took the opportunity to contradict certain rumors which had been cir- 
culated concerning the toxicity of DDT to man and mammals, and considered the exchange of literature and information and the free flow of insecticides among nations.

\section{Second Session}

At the second meeting of the Expert Committee on Insecticides, held in Geneva, October 4-11, 1950 (2), the primary topics of discussion were the disinsectization of aircraft and ships and specification for insecticides and equipment. Other problems considered included the prevention of the reimportation of anophelines into areas freed of this mosquito and the free international flow of insecticides. A joint session was held with the Expert Committee on International Epidemiology and Quarantine to agree on recommendations for disinsectization of ships and vessels in international services.

Recommendations for the disinsectization of aircraft were considerably changed from the ones made at the first session. It was felt that the actual disinsectization procedures then in force were not effective, and that treatment of passenger planes with insecticides was being done in a perfunctory manner. Passengers, in many instances, are not amiable to being exposed to an effective dosage of an insecticide, and for this reason many of the airlines are reluctant to employ adequate treatments. It was felt that disinsectization should be carried out before take-off, with all luggage and/or freight loaded, but without passengers. All ventilators and exterior apertures should be tightly closed during spraying and for at least 5 minutes afterwards. If for any reason, passengers and/or crew have to disembark and reenter the plane after treatment, the spray operation may be repeated at the discretion of the health authority. If adequate disinsectization is not carried out before departure, it may be done with passengers and crew aboard before the plane is landed. However, the disinsectization of planes without passengers aboard is desirable since this permits the use of more effective insecticides and the application of heavier dosages. This procedure may be a step toward fulfilling the requirements of both agriculture and public health procedures.
In addition to disinsectization procedures, antimosquito measures around airports should be rigidly carried out and a system of inspection set up to assure that this is done. It is desired that WHO be kept up to date on information relative to sanitary conditions, including presence or absence of vectors of disease around airports which are open to international traffic.

With reference to disinsectization of ships, it was again considered that antimosquito sanitation of seaports was essential. The committee recommended that the routine treatment of ships arriving in ports in areas declared free of vectors should be abandoned and replaced by routine inspection. Of course, in very small craft, routine treatment is often more economical and less time consuming than inspection. The committee pointed out that since ordinarily treatment will be carried out only on infested vessels, space-spraying may be more appropriate than spraying for residualdeposit effect; however, for ships in regular and frequent services between infested and free ports, residual treatment would probably be the method of choice.

As a space spray for use in the disinsectization of ships, the committee recommended an aerosol of pyrethrins and DDT dispensed at the rate of $10 \mathrm{gm}$. per 1,000 cubic feet of inclosed space. For residual treatment, DDT sprayed at the rate of $200 \mathrm{mg}$. per square foot was advised.

The following specifications for insecticides were recommended:

1. Revision of specifications for technical DDT.

2. Specifications for DDT wettable powder concentrates of 50 percent or over.

3. Tentative specifications for DDT emulsion concentrate of 20 percent and above.

4. Specifications for technical benzene hexachloride (12-14 percent gamma-isomer BHC).

5. Specifications for gamma-isomer benzene hexachloride concentrates of 90 percent and above.

6. Specifications for technical benezene hexachloride wettable powder concentrates (50 percent technical BHC and over). 
7. Tentative specifications for technical agricultural grade and clarified grade chlordan.

8. Guidance information for the purchase of methoxychlor.

In the matter of equipment, specifications were formulated for compression and hand sprayers as established at the first session of the committee. In addition, preliminary specifications for stirrup pumps, which are extensively used in some parts of the world in malaria control activities, were set forth.

The hope was expressed that WHO would meet with success in its endeavors to insure a free flow of insecticides and the waiving of customs duties.

The recommendations of the Expert Committee on Insecticides, when approved by the Executive Board, become official for use by all member nutions of WHO. They do not in any way hamper improvements in techniques or equipment by member nations, but they do insure that nations with insuflicient technical information are given proper guidance in conducting their vector-control programs.

There can be no doubt that the recommendations of the committee have advanced the effectiveness of malaria control in many countries, and future meetings will augment the information already arailable to backward areas. It is hoped that eventually recommendations of the expert committee will encompass all important vector-control problems throughout the world.

A necessary function in accomplishing this feat is a continuing and expanding program of research. The rapid increase in the use of insecticides has given rise to many problems not originally envisaged by either the health authorities or the insecticide manufacturers. Furthermore, practical application in the field of insecticides has gone far ahead of fundamental research. With these considerations in mind, the Expert Committee on Insecticides, at its second session, recommended "that WHO draw the attention of member governments to the fact that, for the practical continuation of disease-vector-control throughout the world, an increase in fundamental research work has become even more imperative than heretofore."

\section{Third Session}

The third session of the Expert Committee on Insecticides met at Savannah, Ga., July 30 to August 4, 1951 (3). The recommendations set forth at this meeting, however, have not been approved by the Executive Board of WHO and, therefore, cannot be reported in detail at this time.

In general, the committee established specifications for stirrup pump type sprayers, hand and rotary dusting apparatus, and certuin types of spray hose. Specifications were also established for spray control valves and hose connections, and a specification chart for compression sprayers was approved. This chart will enable those selecting sprayers to determine the attributes of various commercial norlels with reference to their compliance with WHO specifications.

One of the most valuable pieces of work accomplished by the committee was the establishment of standard nomenclature for types and parts of spraying equipment. The international adoption of these recommendations will alleviate much confusion relative to the purchase and use of spraying equipment. It is sincerely hoped that all governments and manufacturers will adopt these recommendations after their approval by the Executive Board of IVHO, and that future meetings of the Expert Committee will augment the present list of definitions to keep pace with the development of spraying equipment.

"The attainment by all peoples of the highest possible level of health" has become the watchword and the goal of WHO, and the Expert Committee on Insecticides is a potent factor toward accomplishing this end.

\section{REFERENCES}

(1) Expert Committee on Insecticides: Report on the first session. World Health Organization Technical Report Series, No. 4. Geneva, World Health Organization, 1950, 46 pp.

(2) Expert Conmuittee on Insecticides: Report on the second session. World Health Organization Technical Report Series, No. 34. Geneva, World Health Organization, 1951, 82 pp.

(3) Expert Committee on Insecticides: Report on the third session. To be published in the World Health Organization Technical Report Series. 